\title{
Light-Weight Mg/Al Dissimilar Structures Welded by CW Laser for Weight Saving Applications
}

\author{
Qiong $\mathrm{Gao}^{1}$, Sonia $\mathrm{Meco}^{2}$, Kehong Wang ${ }^{1(\mathbb{(})}$, and Shun Guo ${ }^{1}$ \\ ${ }^{1}$ School of Material Science and Engineering, Nanjing University of Science and Technology, \\ Nanjing 210094, People's Republic of China \\ wkh1602@126.com \\ ${ }^{2}$ Welding Engineering and Laser Processing Centre, Cranfield University, University Way, \\ building 46, Cranfield, Bedfordshire MK43 0AL, England, UK
}

\begin{abstract}
With the increasing demand of light-weight alloys, such as magnesium $(\mathrm{Mg})$ and aluminum $(\mathrm{Al})$, the need for joining these two alloys is unavoidable. In this study, AZ31B Mg and $1060 \mathrm{Al}$ alloys were joined by continuous wave laser micro-welding using a $0.05 \mathrm{~mm}$ thick $\mathrm{Cu} / \mathrm{Zn}$ interlayer. The microstructure and phases constituent of the weld seam were examined by optical microscope, SEM and EDS. The formation and distribution of the intermetallic compounds (IMCs) and the relationship between these structures and the microhardness of the weld were discussed in detail. The effect of $\mathrm{Cu} / \mathrm{Zn}$ interlayer on the performance of $\mathrm{Mg} / \mathrm{Al}$ joint was also analyzed. The results showed that $\mathrm{Mg} / \mathrm{Al}$ IMCs were formed in the weld, which indicates that the $\mathrm{Cu} / \mathrm{Zn}$ foil could not prevent the reaction between $\mathrm{Mg}$ and $\mathrm{Al}$. However, the addition of $\mathrm{Cu}$ and $\mathrm{Zn}$ into the weld pool refined the microstructure by improving the number of eutectic structures. The micro-hardness of $\mathrm{Mg} / \mathrm{Al} \mathrm{IMCs}$ in the middle of the weld was very high which can be detrimental to the toughness of the $\mathrm{Mg} / \mathrm{Al}$ joints.
\end{abstract}

Keywords: Magnesium · Aluminum · Laser · Micro-welding · Microstructure · Intermetallic compounds

\section{Introduction}

Light-weight components are of high interest for aerospace and automotive industries because such components permit reducing fuel consumption and ease pressure on the fuel economy. This has led to the development of novel materials and advanced processing techniques. Magnesium and aluminum are preferred for their outstanding performance, low density (light weight) and high strength to weight ratio which are the most important characteristics in the manufacturing industries within the transportation sector. The continuous exploitation of applications for these alloys will lead to a broader use of $\mathrm{Mg} / \mathrm{Al}$ composite structures in order to reduce the total weight of the structures without compromising the required strength [1-3]. However, it is still a challenge to produce reliable $\mathrm{Mg} / \mathrm{Al}$ joints due to their different physical properties and the formation of excessive $\mathrm{Mg}$-Al intermetallic compounds (IMCs) when both metals are mixed together. Hence, the way to produce high quality and high strength $\mathrm{Mg} / \mathrm{Al}$ joints is still 
one of the main research topics worldwide. Previous researchers have focused their work on controlling the reaction between $\mathrm{Mg}$ and $\mathrm{Al}$ to a minimum level to minimize the formation of $\mathrm{Mg}-\mathrm{Al} \mathrm{IMCs}$. The authors have used the following welding processes: TIG [4], spot welding [5], MIG [6], laser [7, 8], laser-MIG hybrid [9], friction stir welding $[10,11]$ and diffusion bonding [12] between others. However, the formation of $\mathrm{Mg} / \mathrm{Al}$ IMCs is still.

Laser processing uses a high power density heat source and offers significant advantages when compared to arc welding low heat input is the main advantage because it not only reduces the distortion [13] but also minimizes the dilution of $\mathrm{Mg}$ into $\mathrm{Al}$ and viceversa. Therefore, laser welding is a promising process to join $\mathrm{Mg}$ to $\mathrm{Al}$. An alternative approach to reduce the formation of $\mathrm{Mg} / \mathrm{Al} \mathrm{IMCs}$ is by changing the chemical composition of the melt pool by using an interlayer and alloying the weld. No research about $\mathrm{Mg} / \mathrm{Al}$ dissimilar welding with $\mathrm{Cu} / \mathrm{Zn}$ interlayers has been carried out. Hence, in this study, $1060 \mathrm{Al}$ alloy and AZ31B Mg alloy were welded by continuous wave (CW) laser welding. The microstructure and composition of the welds were investigated as well as the mechanical properties of the joints.

\section{Experimental Details}

Sheets of 1050 aluminum $(0.5 \times 30 \times 105 \mathrm{~mm})$ and AZ31B magnesium $(1 \times 30 \times 105 \mathrm{~mm})$ were used as base materials in this work. The typical chemical composition of the base metals is shown in Table 1 . Interlayers of $0.05 \mathrm{~mm}$ thick copper brass (63 wt $\% \mathrm{Cu}$ and $37 \mathrm{wt} \% \mathrm{Zn}$ ) were added between the $\mathrm{Mg}$ and $\mathrm{Al}$ sheets. The schematic diagram of the laser welding process set-up is shown in Fig. 1. The Mg sheet was placed on the top of $\mathrm{Al}$ sheet because the absorption of the laser radiation $(1070 \mathrm{~nm}$ of wavelength) by $\mathrm{Al}$ is lower than that of $\mathrm{Mg}$. Thus, the laser process becomes more efficient with $\mathrm{Mg}$ on the top because more energy is absorbed by the material. $\mathrm{Mg}$ and $\mathrm{Al}$ alloys are both active. Thus, shielding gas is generally required during the welding process. In this work pure shield argon was used with $151 /$ min flow rate. Before welding, the surfaces of the base materials were ground with a grinder and degreased with acetone to remove the oxides and oil from the material surface. A CW fibre laser with $3 \mathrm{~kW}$ of maximum power was used. The characteristics of laser is listed in Table 2. The laser beam was characterized using a Primes $\mathrm{GmbH}$ focus monitor system and the $\mathrm{D} 4 \sigma$ method. The optimal parameters were power $525 \mathrm{~W}$, travel speed $96 \mathrm{~mm} / \mathrm{s}$. The characteristics of laser used in this study is listed in Table 2.

Table 1. Chemical compositions [wt $\%$ ] of AZ31B and 1050 alloys.

\begin{tabular}{l|l|l|l|l|l|l|l|l|l|l}
\hline Material & $\mathrm{Al}$ & $\mathrm{Zn}$ & $\mathrm{Mn}$ & $\mathrm{Si}$ & $\mathrm{Fe}$ & $\mathrm{Cu}$ & $\mathrm{Ca}$ & $\mathrm{Cr}$ & $\mathrm{Mg}$ & Other \\
\hline AZ31B & $2.5-3.5$ & $0.6-1.4$ & 0.2 & 0.1 & 0.005 & 0.05 & 0.04 & - & $\mathrm{Bal}$ & 0.3 \\
\hline 1050 & Bal & 0.05 & 0.05 & 0.25 & 0.4 & 0.05 & - & - & 0.05 & 0.10 \\
\hline
\end{tabular}




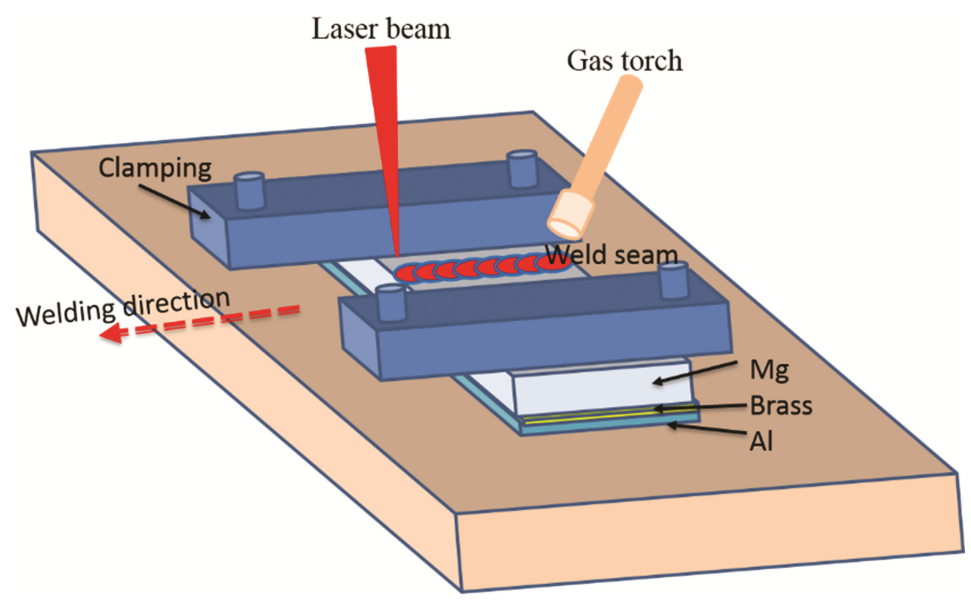

Fig. 1. Schematic of $\mathrm{Mg} / \mathrm{Al}$ laser welding process

Table 2. Laser characteristics

\begin{tabular}{l|l|l|l|l|l}
\hline Laser & $\begin{array}{l}\text { Max. Power } \\
(\mathrm{KW})\end{array}$ & $\begin{array}{l}\text { Wavelength } \\
(\mathrm{nm})\end{array}$ & Focusing lens & $\begin{array}{l}\text { Delivery fiber } \\
(\mu \mathrm{m})\end{array}$ & $\begin{array}{l}\text { Beam } \\
\text { diameter }(\mu \mathrm{m})\end{array}$ \\
\hline Fiber laser & 3 & 1070 & FL 300 & 100 & 192 \\
\hline
\end{tabular}

After welding, the cross sections of the $\mathrm{Mg} / \mathrm{Al}$ joints were prepared for microstructural analysis. The samples were ground and polished by abrasive papers and diamond polishing paste, following standard metallographic procedure. The micrographs of the full section of the welds were taken by a camera installed in the optical microscope. The microstructure of the welds was observed under a scanning electron microscope (SEM) (FEI Quanta 250F environment scanning electronic telescope) equipped with an energy dispersive $\mathrm{x}$-ray spectrometer (EDS). The composition and distribution of the IMCs present in the joints were determined by EDS. Micro-hardness tests were carried out by a Vickers hardness tester (HVS-1000Z) with $0.98 \mathrm{~N}$.

\section{Results and Discussion}

\subsection{Macrostructure of Mg/Al Joint}

The initial observation of the results indicates that $\mathrm{Mg}$ and $\mathrm{Al}$ alloys can be successfully welded by $\mathrm{CW}$ laser welding with brass foil. The appearance of the $\mathrm{Mg} / \mathrm{Al}$ joint with brass interlayer can be seen in Fig. 2. The micrograph shows a smooth weld seam with no visible defects. Due to the small laser beam diameter $(192 \mu \mathrm{m})$ the width of weld seam is extraordinary small, nearly $1 \mathrm{~mm}$ wide, which is much smaller than the width of the weld seams produced by the arc welding processes, normally (10 mm wide). 


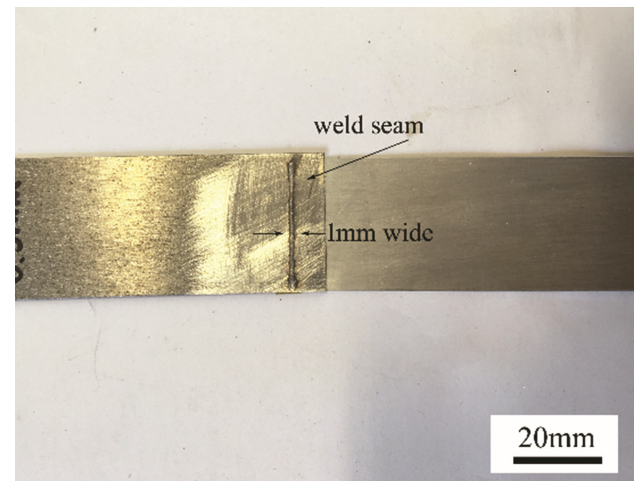

Fig. 2. Appearance of weld surface

The cross section of the weld is shown in Fig. 3. The weld seam is $943.3 \mu \mathrm{m}$ wide and $1450.6 \mu \mathrm{m}$ deep, which means that the weld is not fully penetrating. It is also clear that the microstructure within the melt pool is not uniform because different zones with different colours can be observed under the optical microscope. The dark, light black and white zones are set as zone A, B, C, respectively. The EDS elemental mapping is presented in Fig. 4(b), (c). It is clearly seen that every element is unevenly distributed within the weld pool. Mg diffused into $\mathrm{Al}$ substrate and was mixed with $\mathrm{Al}$. The elements from the interlayer, $\mathrm{Cu}$ and $\mathrm{Zn}$, are evenly dispersed in the weld. The uneven distribution of each element explains the distinct zones with different colours visible in the micrograph. The chemical composition of each zone was investigated by SEM and EDS analysis. The results are discussed as follows.

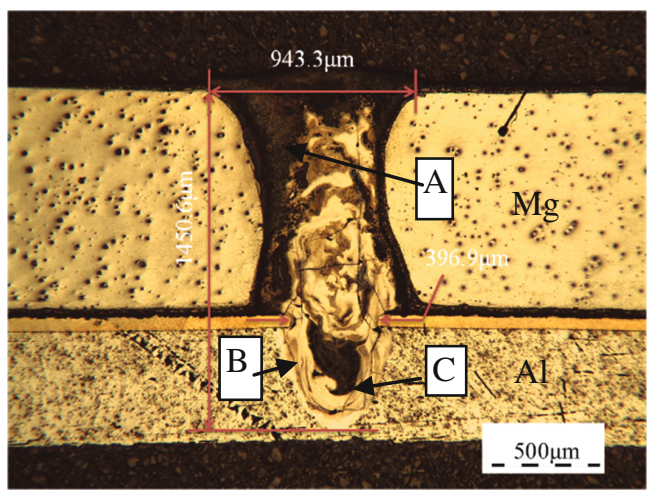

Fig. 3. Morphology of weld cross section 


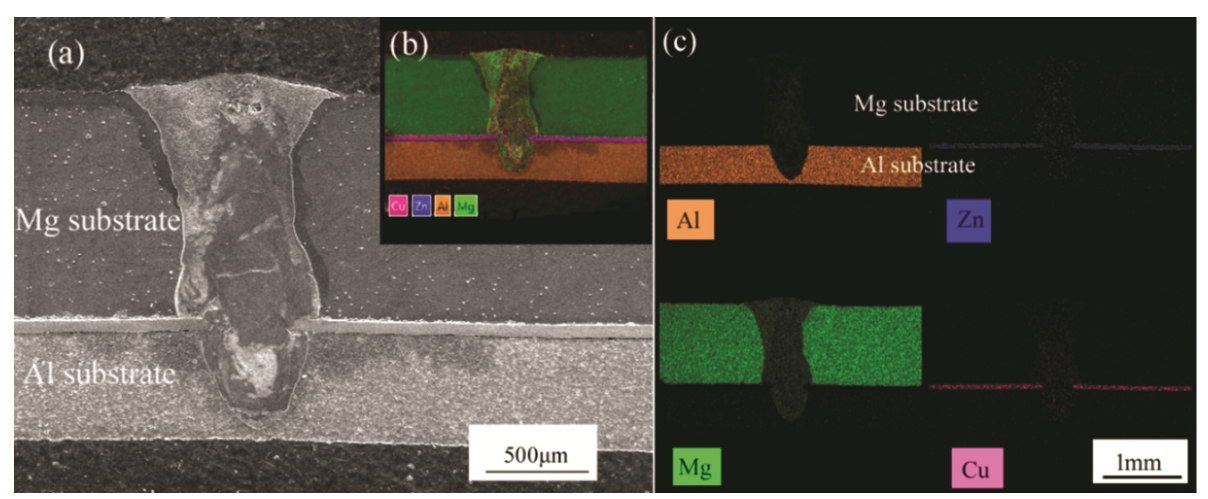

Fig. 4. (a) SEM morphology of weld, (b) EDS mapping picture, (c) EDS mapping pictures for $\mathrm{Al}, \mathrm{Mg}, \mathrm{Zn}, \mathrm{Cu}$, respectively.

\subsection{Microstructure of Mg/Al Joint}

Figure 5(a) shows the SEM micrographs of zone A in Fig. 3. Figure 5(b) presents the microstructure of the interface and bottom of the weld. The micrographs with higher magnification of zones I, II, III in Fig. 5(b) are shown in Fig. 5(c), (d), (e), respectively. The chemical composition of the points 1 to 6 in Fig. 6 is listed in Table 3. The grey dendritic crystal shown in Fig. 5(a) (point 1) is composed by 76.8 at \% Mg, 20 at \% $\mathrm{Al}$, 1.6 at $\% \mathrm{Zn}$ and 1.6 at \% $\mathrm{Cu}$. This phase has been identified as Mg-based solid solution and $\mathrm{Mg}$-Al eutectic structure, according to the $\mathrm{Mg}$-Al binary phase diagram (see Fig. 6). According to Fig. 5(c), the microstructure of zone I (zone B in Fig. 3) is mainly composed by a continuous IMC with dendritic structure, identified as Al12Mg17. However, eutectic structures were found to segregate the continuous dendrite to a dispersed and small size dendrite matrix. It can be indicative that the $\mathrm{Cu}$ and $\mathrm{Zn}$ has a high tendency to form the eutectic dendritic structures. Figure 5(d) shows the microstructure of the bottom of weld which turned to be eutectic dendritic corresponding to zone $\mathrm{C}$ in Fig. 3. Point 3 is composed by 19.4 at \% Mg, 75.7 at \% Al, 1.5 at \% $\mathrm{Zn}$, and 3.4 at \% Cu, which is considered as Al-based solution and $\mathrm{Al}_{3} \mathrm{Mg}_{2} \mathrm{IMCs}$. The content of $\mathrm{Cu}$ in point 3 is higher than that in point 1 . That could be explained by the solubility of $\mathrm{Cu}$ in $\mathrm{Al}$ to be higher than that in $\mathrm{Mg}$. More $\mathrm{Cu}$ has been dissolved in $\mathrm{Al}$ solution. The composition in point 4 is 36.4 at $\% \mathrm{Mg}, 59.4$ at \% $\mathrm{Al}, 1.5$ at \% $\mathrm{Zn}$ and 2.7 at \% $\mathrm{Cu}$ corresponding to $\mathrm{Mg}$ based solution and $\mathrm{Al}_{12} \mathrm{Mg}_{17}$ eutectic structure. The magnified morphological features of zone III is presented in Fig. 5(e), which shows two parallel structures with different morphologies. In point 5 , the microstructure has lamellar eutectic structures regarded as $\mathrm{Mg}$ - $\mathrm{Al}$ eutectic $\left(\mathrm{Al}_{3} \mathrm{Mg}_{2}, \mathrm{Al}_{12} \mathrm{Mg}_{17}\right.$ and $\mathrm{Mg}$ based solution). In addition, the microstructure in Point 6 is a cellular crystal with composition of 54.7 at $\% \mathrm{Mg}, 41.6$ at $\% \mathrm{Al}$, 2.1 at $\% \mathrm{Zn}$ and 1.6 at $\% \mathrm{Cu}$, which can be considered as $\mathrm{Mg}$ based solution and $\mathrm{Al}_{17} \mathrm{Mg}_{12}$. 

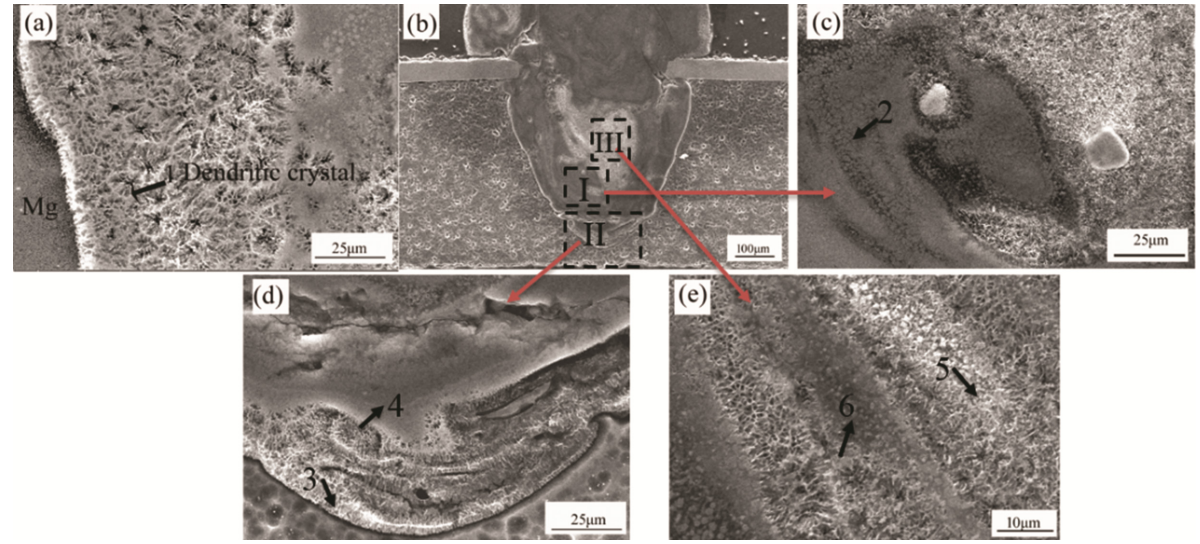

Fig. 5. (a) Microstructure of the top of weld seam, (b) microstructure of interface and bottom of the weld seam, (c) magnified picture of zone I, (d) magnified picture of zone II, (e) magnified picture of zone III.

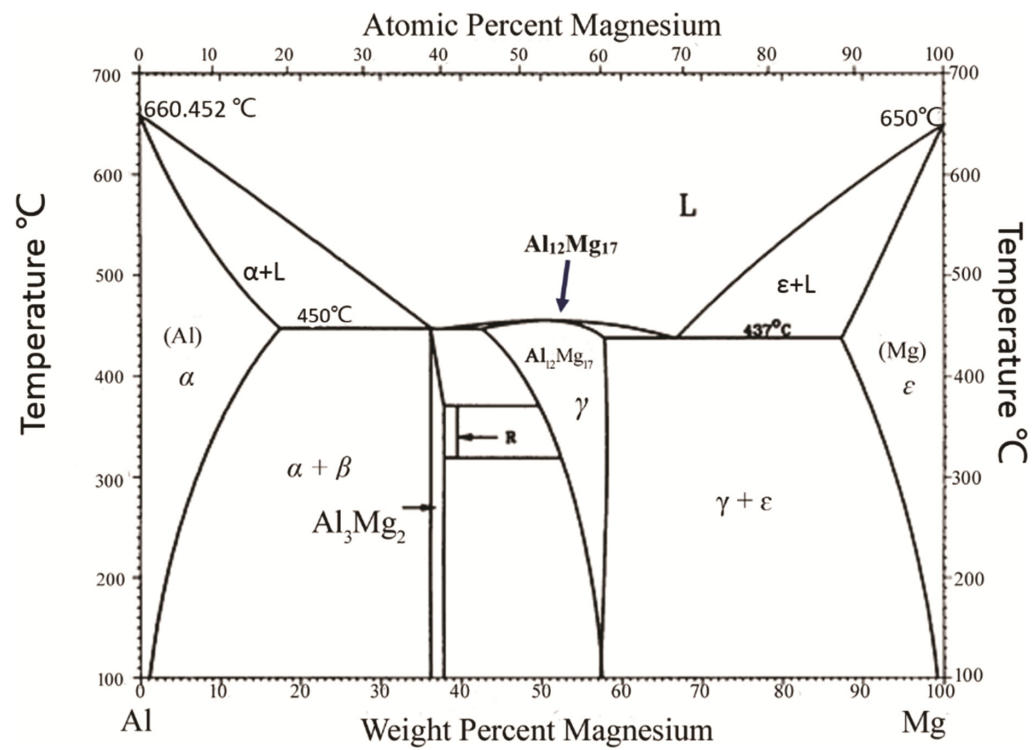

Fig. 6. $\mathrm{Mg}$ and $\mathrm{Al}$ binary phase diagram

It can be concluded that the addition of $0.5 \mathrm{~mm}$ brass interlayer could not prevent the diffusion of $\mathrm{Mg}$ and $\mathrm{Al}$ due to the full fusion of both alloys, $\mathrm{Mg}$ and $\mathrm{Al}$. The addition of $\mathrm{Cu}$ and $\mathrm{Zn}$ element promoted the formation of branch crystals. In Fig. 3, the darker phase corresponded to higher content of Mg. Hence, the darkness feature in Fig. 4 (zone A) is $\mathrm{Mg}$ based solution and eutectic structure. The light dark feature in zone B in Fig. 3 is a mixture of $\mathrm{Mg}$ and $\mathrm{Al}$ which corresponds to $\mathrm{Mg}$-Al IMCs. The white structures in zone $\mathrm{C}$ of Fig. 3 were $\mathrm{Al}$ based solution and eutectic structures. 
Table 3. Phases Composition at.\%

\begin{tabular}{l|l|l|l|l|l}
\hline Point & $\mathrm{Mg}$ & $\mathrm{Al}$ & $\mathrm{Zn}$ & $\mathrm{Cu}$ & Possible Phase \\
\hline 1 & 76.8 & 20.0 & 1.6 & 1.6 & $\mathrm{Mg}$ solid solution and $\mathrm{Mg}-\mathrm{Al}$ eutectic structure \\
\hline 2 & 51.2 & 43.4 & 3.3 & 2.1 & $\mathrm{Al}_{12} \mathrm{Mg}_{17}$ \\
\hline 3 & 19.4 & 75.7 & 1.5 & 3.4 & $\mathrm{Al}$ solid solution and $\mathrm{Mg}-\mathrm{Al}$ eutectic structure \\
\hline 4 & 36.4 & 59.4 & 1.5 & 2.66 & $\mathrm{Mg}_{2} \mathrm{Al}_{3}$ \\
\hline 5 & 60.1 & 31.6 & 1.7 & 5.7 & $\mathrm{Al}_{3} \mathrm{Mg}_{2}, \mathrm{Al}_{12} \mathrm{Mg}_{17}$ and $\mathrm{Mg}$ based solution \\
\hline 6 & 54.7 & 41.6 & 2.1 & 1.6 & $\mathrm{Mg}$ based solution and $\mathrm{Al}_{17} \mathrm{Mg}_{12}$ \\
\hline
\end{tabular}

\subsection{Micro-hardness Analysis}

The micro-hardness distribution of the weld seam has an important effect on the performance of the joint. Based on the micro-hardness of the weld it is possible to infer the strength and identify the weakest points on the joints. Figure 7(c) shows the direction and relative position of the indentations to the weld pool. The micro-hardness distribution along the vertical path, represented by line 1, is shown in Fig. 7(a), while the micro-hardness distribution along the horizontal path, represented by line 2 is drawn in Fig. 7(b). In Fig. 7(a), the micro-hardness in the middle of the weld seam is higher, above $300 \mathrm{HV}$, than that in the top and bottom of the weld seam. According to the previous analysis of the microstructure, the phase composition in the top of the weld seam is Mg-based solution and eutectic structure. Therefore, the micro-hardness in this zone is lower than others but higher than that of $\mathrm{Mg}$ substrate. The feature in the middle of the weld is a mixture of $\mathrm{Mg}$ and $\mathrm{Al}$ as a form of $\mathrm{Mg}$ and Al IMCs which explains the higher micro-hardness. However, the value of the micro-hardness in the middle of the weld is not constant. The drop-down values confirms that the phase composition is not continuous. In the Al side, the average micro-hardness of the weld is lower due to the formation of Al based solution and eutectic structures.

In Fig. 7(b), the micro-hardness of weld seam near fusion line is about $150 \mathrm{HV}$, which is lower than the value in middle of weld seam but higher than that of the Al alloy. One possible reason is that in that zone the branch crystal is an Al based solution which has a relatively low value of micro-hardness. This can have a positive impact on the toughness of $\mathrm{Mg} / \mathrm{Al}$ joint. In the middle of the weld, the micro-hardness reaches just above $300 \mathrm{HV}$ due to the formation of $\mathrm{Mg} / \mathrm{Al} \mathrm{IMCs}$. 

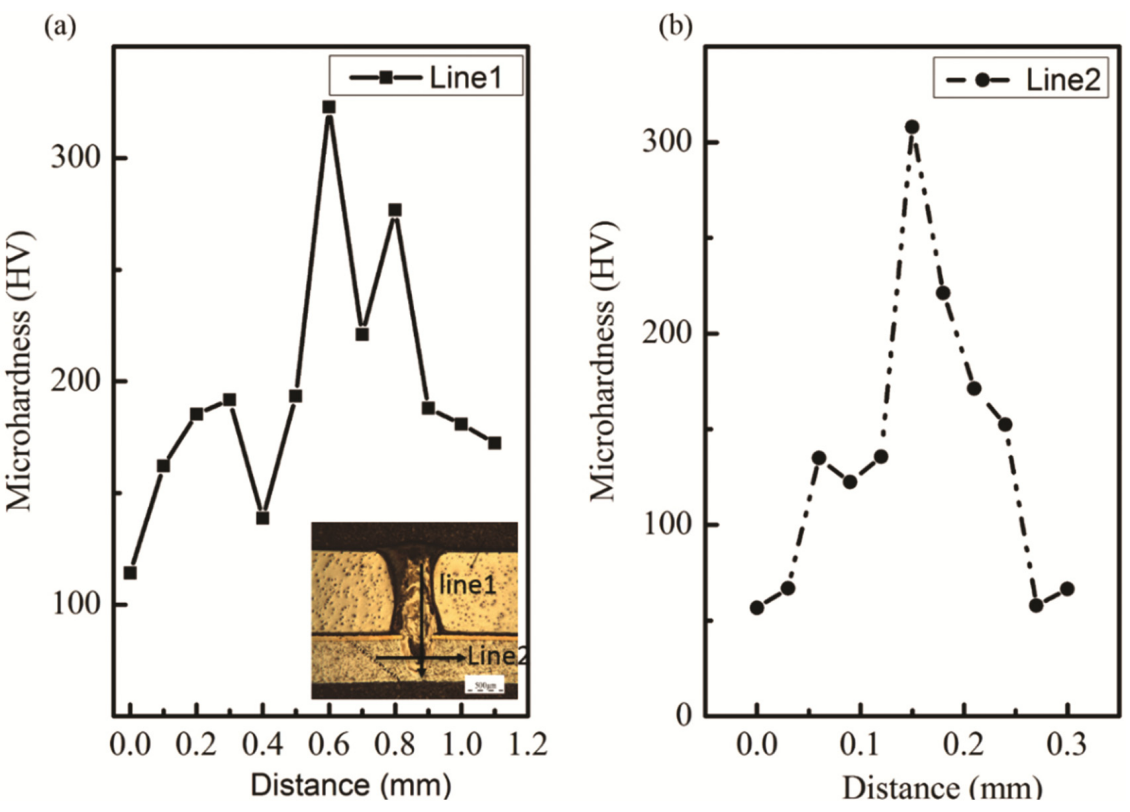

Fig. 7. (a) Microhardness of line 1, (b) microhardness of line 2, (c) the schematic diagram of microhardness test

\section{Conclusion}

AZ31B Mg and $1060 \mathrm{Al}$ thin sheets were successfully joined by CW laser micro-welding using $\mathrm{Cu} / \mathrm{Zn}$ composite interlayer. The addition of $0.05 \mathrm{~mm}$ thick $\mathrm{Cu} / \mathrm{Zn}$ interlayer could not avoid the formation of $\mathrm{Mg} / \mathrm{Al} \mathrm{IMCs}$ but refined the microstructure of weld seam (improve the formation of dendritic structure), which can improve the toughness of $\mathrm{Mg} / \mathrm{Al}$ joints.

The microstructure of weld seam was uneven and formed by different phases. In the top of weld, zone A was composed of Mg-based solution, zone B was composed of $\mathrm{Mg} / \mathrm{Al} \mathrm{IMCs}$ and zone $\mathrm{C}$ composed of Al-based solution.

The distribution of IMCs in the weld seam affects the micro-hardness. The microhardness in zone $\mathrm{A}$, top of the weld pool, was lower than that of the $\mathrm{Mg}$ and $\mathrm{Al}$ mixture region composed of $\mathrm{Mg} / \mathrm{Al} \mathrm{IMCs}$. The micro-hardness on the sides of the weld seam was lower than that in the middle of weld due to the formation of solid solution, which indicates that the increasing number of solid solution can improve the toughness of $\mathrm{Mg} / \mathrm{Al}$ joint. 


\section{References}

1. Schubert, E., Klassen, M., Zerner, I., Walz, C., Sepold, G.: Light-weight structures produced by laser beam joining for future applications in automobile and aerospace industry. J. Mater. Proc. Tech. 115, 2-8 (2001)

2. Miller, W.S., Zhuang, L., Bottema, J., Wittebrood, A.J., De Smet, P., Haszler, A., Vieregge, A.: Recent development in aluminum alloys for the automotive industry. Mater. Sci. Eng., A 280, 37-49 (2000)

3. Mordike, B.L., Ebert, T.: Magnesium: properties-applications-potential. Mater. Sci. Eng., A 302, 37-45 (2001)

4. Zhang, H.T., Dai, X.Y., Feng, J.C.: Joining of aluminum and magnesium via pre-roll-assisted A-TIG welding with Zn interlayer. Mater. Lett. 122, 49-51 (2014)

5. Macwan, A.: D.L. Chen.: Ultrasonic spot welding of rare-earth containing ZEK100 magnesium alloy to 5754 aluminum alloy. Mater. Sci. Eng., A 666, 139-148 (2016)

6. Wang, J., Feng, J.C., Wang, Y.X.: Microstructure of Al-Mg dissimilar weld made by cold metal transfer MIG welding. Mater. Sci. Tech. 24, 827-831 (2008)

7. Liu, L., Wang, H.: Microstructure and Properties Analysis of Laser Welding and Laser Weld Bonding Mg to Al Joints. Meta. Mater. Trans. A 42, 1044-1050 (2011)

8. Scherm, F., Bezold, J., Glatzel, U.: Laser welding of Mg alloy MgAl3Zn1 (AZ31) to Al alloy AlMg3 (AA5754) using ZnAl filler material. Sci. Tech. Weld. Join. 17, 364-367 (2012)

9. Liu, L.M., Liu, X.J., Liu, S.H.: Microstructure of laser-TIG hybrid welds of dissimilar Mg alloy and Al alloy with Ce as interlayer. Scrip. Mater. 55, 383-386 (2006)

10. Liang, Z., Qin, G., Wang, L., Meng, X., Li, F.: Microstructural characterization and mechanical properties of dissimilar friction welding of 1060 aluminum to AZ31B magnesium alloy. Mater. Sci. Eng., A 645, 170-180 (2015)

11. Champagne III, V.K., West, M.K., Rokni, M.R., Curtis, T., Champagne Jr., V., McNally, B.: Joining of Cast ZE41A Mg to wrought 6061 al by the cold spray process and friction stir welding. J. Therm. Spray. Tech. 25, 143-159 (2016)

12. Shang, J., Wang, K.H., Zhou, Q., Zhang, D.K., Huang, J., Ge, J.Q.: Effect of joining temperature on microstructure and properties of diffusion bonded $\mathrm{Mg} / \mathrm{Al}$ joints. Trans. Non. Metal. Soc. China 22, 1961-1966 (2012)

13. Meco, S., Ganguly, S., Williams, S., Mcpherson, N.: Effect of laser processing parameters on the formation of intermetallic compounds in Fe-Al dissimilar welding. J. Mater. Per. Eng. 23, 3361-3370 (2014) 
2017-08-25

Light-weight $\mathrm{Mg} / \mathrm{Al}$ dissimilar structures

welded by CW laser for weight saving applications

Gao, Qiong

Springer

Gao Q, Meco S, Wang K, Guo SG. Light-weight Mg/Al dissimilar structures welded by CW laser for weight saving applications. In: Fei M., Ma S., Li X., Sun X., Jia L., Su Z. (eds) Advanced Computational Methods in Life System Modeling and Simulation. ICSEE 2017, LSMS 2017. Communications in Computer and Information Science, Volume 761, Springer, Singapore, pp. 349-357 https://doi.org/10.1007/978-981-10-6370-1_35

Downloaded from Cranfield Library Services E-Repository 